\title{
PENDIDIKAN KARAKTER DALAM MEMBENTUK PERILAKU SUSILA ANAK SEKOLAH DASAR
}

\author{
I PUTU GEDE PARMAJAYA \\ Sekolah Tinggi Agama Hindu Negeri Mpu Kuturan Singaraja
}

\begin{abstract}
Indonesian life corresponding 1945 aspired not yet achieved its full potential . Various cases ranging from sexual abuse, crime, corruption, human trafficking, peraktik prostitution, looting, promiscuity, rampant levels of violence children and adolescents, crimes against friend, theft teens, the habit of cheating, drug abuse, pornography, and environmental destruction, until the murder has not been solved by the security forces and the Indonesian government. Efforts could be done to overcome this phenomenon is the way to improve the character of each individual through character education should start at an early age formed. In elementary school character education can be transformed through learning in the classroom and through extracurricular activities and cooperation between education centers tri component ( family, school and community) are expected cultivation of character education can be implemented optimally.
\end{abstract}

\section{A. PENDAHULUAN}

Kehidupan bangsa Indonesia sesuai UUD 1945 yang dicita-citakan belum dicapai secara maksimal. Berbagai kasus mulai dari pelecehan seksual, kriminalitas, korupsi perdagangan manusia, peraktik prostitusi, penjarahan, pergaulan bebas, maraknya angka kekerasan anak-anak dan remaja, kejahatan terhadap teman, pencurian remaja, kebiasaan menyontek, penyalahgunaan

pornografi, dan perusakan lingkungan, hingga pembunuhan belum dapat diatasi oleh aparat keamanan dan pemerintah Indonesia. Hal ini diasumsikan bisa terjadi akibat manusia/ masyarakat telah mengalami degradasi moral, rendahnya akhlak manusia dan belum terimplemntasinya ajaran moral dan budi pekerti. Masyarakat Indonesia seolah-olah telah kehilangan karakter dan jati dirinya sebagai masyarakat berbudaya dan beradab dan sebagai bangsa yang menjunjung tinggi nilai-nilai pancasila.. Di dalam kondisi carut marutnya keperibadian bangsa, maka generasi muda merupakan harapan yang seharusnya dapat membawa perubahan ke arah yang lebih baik. Generasi muda yang diharapkan adalah generasi muda yang unggul, bermoral dan berkarakter.

Salah satu upaya yang dapat dilakukan untuk menghasilkan manusia yang unggul, bermoral dan berkarakter, salah satunya adalah melalui p[eningkatan kualitas pendidikan. Melihat fenomena yang terjadi saat ini, maka bisa dikatakan bahwa pendidikan di Indonesia belum sepenuhnya bisa menjawab fenomena yang terjadi di negeri tercinta ini. Dengan kata lain bahwa pendidikan di Indonesia belum sepenuhnya mmampu mendidik masyarakatnya untuk menjadi masyarakat yang berkarakter seperti dicanangkan oleh pemerintah melalui upaya pendidikan. 
Untuk membentuk dan menjadikan bangsa Indonesia yang bermoral dan berkarakter, maka salah satunya adalah dengan jalan menerapkan pendidikan karakter disemua jenjang pendidikan. Penuangan pendidikan moral (moral education) atau pendidikan karakter (character education) dimasa global seperti sekarang cukup relevan dilakukan dalam upaya mengatasi krisis dan degradasi moral yang dialami anak bangsa dewasa ini.

Dengan meminjam pendapat Lickona bahwa karakter berkaitan dengan konsep moral (moral knonwing), sikap moral (moral felling), dan perilaku moral (moral behavior). Ketiga komponen karakter di atas menyatakan bahwa untuk menjadikan manusia berkarakter yang baik harus didukung oleh pengetahuan tentang kebaikan, keinginan untuk berbuat baik, dan melakukan perbuatan kebaikan. Jika dikaitkan dengan pendidikan Hindu, maka di dalam konsep Hindu ada yang disebut tri kaya parisudha (tiga perilaku berdasarkan atas pikiran yang baik, perkataan yang baik dan perbuatan yang baik.

Uraian di atas seuai dengan pendapat Dantes, (2014:74) bahwa karakter berkaitan dengan pengetahuan moral, perasaan moral dan perilaku moral. Karakter yang baik terdiri atas pengetahuan yang baik, keinginan untuk berbuat baik, dan berbuat kebaikan, atau kebiasaan pikiran, kebiasaan perasaan dalam hati dan kebiasaan berperilaku yang baik. Tirtarahardja, (2005:7) bahwa moral adalah yang sinkron dengan kata hati yang tajam yaitu yang benar-benar baik bagi manusia, sebagai manusia merupakan moral yang baik atau moral yang tinggi (luhur). Sebaliknya perbuatan yang tidak sinkron dengan kata hati yang tajam ataupun merupakan realisasi dari kata hati yang tumpul disebut moral yang buruk atau moral yang rendah (asor) atau lazim dikatakan tidak bermoral. Seseorang dikatakan bermoral tinggi karena ia menyatukan diri dengan nilai-nilai yang tinggi, serta segenap perbuatannya merupakan peragaan dari nilai-nilai yang tinggi tersebut. Moral bertalian erat dengan keputusan kata hati, yang dalam hal ini bertalian erat dengan nilai-nilai, maka sesungguhnya moral itu adalah nilai-nilai kemanusiaan

Berdasarkan uraian di atas pendidikan karakter seharusnya dilakukan di lingkungan pendidikan keluarga, sekolah dan masyarakat. Di lingkungan pendidikan formal, pendidikan karakter harus diberikan pada anak usia Play Group (PG), Pendidikan Anak Usia Dini (PAUD), Taman Kanak-Kanak (TK) dan Sekolah Dasar (SD). Hal ini disebabkan karena pada masa-masa usia tersebut merupakan masa peka untuk menerima berbagai bentuk pendidikan yang baik, agar bisa dikembangkan ke jenjang pendidikan selanjutnya. Dengan pondasi pendidikan karakter yang baik diasumsikan akan dibawa pada usia siswa semakin dewasa.

\section{B. PEMBAHASAN}

\section{Pengertian karakter}

"We don't want them to lie, cheat on tests, take what's not theirs, call names, hit each other, or be cruel to animals; we do want them to tell the truth, play fair, be polite, respect their parents and teachers, do their schoolwork, ad be kind to others. (1991:47). Artinya dengan mengutamakan nilai kejujuran, tentu 
siswa diminta untuk tidak mencontek saat mengerjakan tugas atau ujian, tidak mengambil barang yang bukan haknya, memanggil dengan panggilan yang baik, menyayangi teman, dan memperlakukan hewan dengan baik. Dengan demikian, jelas bahwa kita menginginkan agar peserta didik kita berkata jujur (tidak bohong), adil, sopan santun, menghormati orang tua dan guru, mengerjakan tugas sekolah yang diberikan oleh guru, dan bersikap baik kepada setiap orang.

Lickona menegaskan sebagai berikut.

Character so conceived has three interrelated parts: moral knowing, moral feeling, and moral behavior. Good character consists of knowing the good, desiring the good, and doing the good, habits of the mind, habits of the heart, and habits of action. All three are necessary for leading a moral life, all three make up moral maturity. When we think about the kind of character we want for our children, it's clear that we want them to be able to judge what is right, care deeply about what is right, and then do what they believe to be right, even in the face of pressure from without and temptation from within. (1991: 51)

Berdasarkan penjelasan Lickona di atas dapat dijelaskan bahwa karakter terdiri atas tiga aspek yaitu moral knowing, moral feeling, dan moral behavior. Dengan demikian maka karakter meliputi hal-hal sebagai berikut (1) mengetahui halhal yang baik, (2) keinginan untuk berbuat baik, dan (3) melaksanakan yang baik berdasarkan atas pikiran, dan perasaan.Jika ketiga hal di atas mampu dilaksanakan, maka manusia diasumsikan bisa bersikap dewasa dan bermoral.

Menurut Sigmund Freud (dalam Zaenal Abidin 2011: 30) "character is a striving system which underly behaviour. Karakter adalah kumpulan tata nilai yang terwujud dalam suatu sistem daya dorong (daya juang) yang melandasi pemikiran, sikap dan perilaku yang ditampilkan secara mantap Menurut Hardiman (2001: 70) pendidik dan psikolog yang terlibat dalam pendidikan karakter mendefinisikan karakter sebagai sifat-sifat suatu keperibadian yang tunduk pada sanksi-sanksi moral dari masyarakat.

Karakter merupakan aktualisasi perilaku baik yang muncul dari potensi diri seseorang serta diinternalisai dalam bentuk nilai-nilai moral yang menjadi bagian dari kepribadian seseorang. Karakter bisa berupa nilai-nilai yang yang melekat pada diri seseorang yang diperoleh melalui proses pendidikan, pola asuh, dan pengaruh lingkungan. Nilai-nilai yang sudah ada tersebut kemudian melandasi sikap dan perilaku seseorang dalam kehidupannya. Karakter tidak datang dengan sendirinya melainkan harus dibentuk, ditumbuhkembangkan dan dibangun melalui proses pendidikan dan pembiasaan. Menurut Mendiknas (2011: 8), terdapat sembilan pilar karakter yaitu (1) karakter cinta Tuhan dan segenap ciptaan-Nya, (2) kemandirian dan tanggung jawab, (3) kejujuran/ amanah dan diplomatis, (4) hormat dan santun, (5) dermawan dan suka tolong-menolong dan gotong royong/kerjasamaPercaya diri dan 
pekerja keras, (6) kepemimpinan dan keadilan, (7) 8aik dan rendah hati, dan (9) karakter toleransi, kedamaian dan kesatuan.

\section{Prinsip Pendidikan Karakter}

Menurut Lickona (dalam Kemendiknas 2011: 11) terdapat sebelas prinsip agar pendidikan karakter dapat berjalan efektif, yaitu (1) kembangkan nilai-nilai etika inti dan nilai-nilai kinerja pendukungnya sebagai pondasi karakter yang baik, (2) efinisikan "karakter" secara komperhensif yang mencakup pikiran, perasaan dan perilaku, (3) gunakan pendekatan yang komperhensif, disengaja dan proaktif dalam pengembangan karakter, (4) ciptakan komunitas sekolah yang penuh perhatian, (5) beri peserta didik kesempatan untuk melakukan tindakan moral, (6) buat kurikulum akademik yang bermakna dan menantang yang menghormati semua peserta didik, mengembangkan karakter dan membantu peserta didik untuk berhasil, (7) usahakan mendorong motivasi diri peserta didik, (8) libatkan staf sekolah sebagai komunitas pembelajaran dan moral untuk berbagi tanggung jawab dalam pendidikan karakter dan untuk mematuhi nilai-nilai inti yang sama dalam membimbing pendidikan peserta didik, (9) tumbuhkan kebersamaan dalam kepemimpinan moral dan dukungan jangka panjang bagi inisiatifpendidikan karakter, (10) libatkan anggota keluarga dan masyarakat sebagi mitra dalam upaya pembangunan karakter dan (11) evaluasi karakter sekolah, fungsi staf sekolah sebagai pendidik karakter, dan sejauh mana peserta didik memanifestasikan karakter yang baik.
Berdasarkan prinsip pendidikan karakter di atas, maka untuk menjadikan pendidikan karakter menjadi efektif maka guru dan staf sekolah harus mampu menjadi model pendidikan karakter yang baik. Artinya untuk menanamkan pendidikan karakter kepada peserta didik, maka guru dan staf sekolahnya dulu yang harus berkarakter. Guru dan staf sekolah harus menjadi model dalam pendidikan karakter. Sebagai ilustrasi jika peserta didik dituntut untuk bersusila/beretika dalam berbicara, maka guru dan staf sekolah terlebih dahulu harus berbicara ynag sopan dan santun. Jika hal ini mampu dilakukan, maka untuk menerapkan pendidikan karakter kepada peserta didik akan mudah dilakukan.

Menurut Kemendiknas (2010: 11-13) ada empat prinsip yang digunakan dalam penegmbangan pendidikan karakter, yaitu:

a. Berkelanjutan mengandung makna bahwa proses pengembangan nilai-nilai karakter merupakan sebuah proses panjang dimulai dari awal peserta didik masuk sampai selesai dari satuan pendidikan.

b. Melalui semua mata pelajaran, pengembangan dan budaya satuan pendidikan.

Prinsip ini memiliki makna bahwa proses pengembangan karakter dilakukan melalui setiap mata pelajaran, dan dalam setiap kegiatan kurikuler, eksrtakurikuler dan ko-kurikuler.

c. Nilai tidak diajarkan tetapi dikembangkan melaui proses belajar. Prinsip ini mengandung makna bawa materi nilai-nilai karakter bukanlah bahan ajar biasa. Tidak semata semata dapat ditangkap sendiri atau 
diajarkan, tetapi lebih jauh di internalisasi melalui proses belajar.

d. Proses belajar dilakukan peserta didik secara aktif dan menyenangkan. Prinsip ini menyatakan bahwa proses pendidikan karakter dilakukan oleh peserta didik bukan pendidik. Prinsip ini juga menyatakan bahwa proses pendidikan dilakukan dalam suasana belajar yang menimbulkan rasa senang.

\section{Tujuan Pendidikan Karakter}

Mendiknas

(2011: mengemukakan bahwa pemebentukan karakter merupakan salah satu tujuan pendidikan nasional. Di dalam pasal $1 \mathrm{UU}$ Sisdiknas tahun 2003 juga telah disebutkan bahwa di antara tujuan pendidikan nasional adalah mengembangkan potensi peserta didik untuk memiliki kecerdasan dan akhlak mulia.

Menurut Dharma Kesuma (2011:17), tujuan pendidikan karakter adalah sebagai berikut (1) memfasilitasi penguatan dan pengembangan nilai-nilai tertentu sehingga terwujud dalam perilaku anak, baik ketika proses sekolah maupun setelah proses sekolah (setelah lulus dari sekolah), (2) mengoreksi perilaku peserta didik yang tidak bersesuaian dengan nilainilai yang dikembangkan masyarakat, dan (3) membangun koneksi yang harmoni dengan keluarga dan masyarakat dalam memerankan tanggung jawab pendidikan karakter secara bersama.

Dalam hal ini nilai-nilai susila atau nilai-nilai etika harus selalu ditanamkan. Dalam ajaran Hindu yang menjadi inti ajaran susila/etika adalah ajaran tri kaya parisudha. Jika ajaran tri kaya parisudha dapat ditanamkamkan sejak SD bahkan mulai dari anak masuk pra sekolah (PAUD), maka diasumsikan dapat dapat membentuk perilaku moral yang baik pada masa anak sekolah dan setelah nak lepas dari proses belajar di sekolah.

Di dalamlontar Tri Kaya Parisudha/Resi Sesana, 1bditegaskan seperti di bawah ini.

Nihan Sang Hyang Tri kaya Parisudha, Nga tiga pakaranya, lwirnya tan kalen maka tapan Sang Hyang dharma, tanpa dosanya mwang tanpa guru ramma, Reka kadawayanta pwekanak wangsanaktā kabeh.

$\mathrm{tt}: 1)$

(Sujana,

Terjemahan:

Inilah Sang Hyang Tri Kaya Parisudha namanya. Ada tiga bagiannya seperti tiada lain sebagai wujud tapanya Sang Hyang Dharma. Selalu membuat senang kepada anak dan cucunya, beserta keturunannya. Demikian juga tidak terkena oleh segala kekotoran yang ada dalam dirinya.

(Parmajaya, 2015)

Selanjutnya di dalam lontar Tri Kaya Parisudha/Resi Sesana 2a ditegaskan seperti berikut.

Sang Hyang Tri Kaya Parisudha de sang sewaka dharma, mangkana ling sang pand $\square$ ita

Nolhyata 
http://ejournal.ihdn.ac.id/index.php/A

patakoning ala lawan hayu, śabdha tan patūt ikā mahala śabdha patūt ikā hayu, mangkana kalinganta, hana Sang Hyang Daśa Śilā ngaranya, ika pakatonan hala hayuning ulah śabdha lawan ambêk, lwirnya nihan, cakşu, śrote, grana, twak, jihwa, pada, payu, pasta, wak nahan tikang dwa daśa puluh wiji de tunggal wişayanya ikā, ndhya pratykanya patunggalaning wişanya, sugyan mangkanā lingta sang para nihan.

(Sujana, tt:2)

Terjemahan.

Melaksanakan ajaran Sang Hyang Tri Kaya Parisudha oleh orang yang menjunjung tinggi kebenaran. Demikian sabda Sang Pandita. Ada pertanyaan baik dan buruk, segala perkataan yang tidak baik adalah dosa besar, perkataan yang benar adalah baik, demikianlah kebenarannya, ada Sang Hyang Dasa Sila namanya. Itu adalah wujud segala perkataan dan perbuatan baik dan buruk, seperti : mata, bibir, hidung, lidah , tangan, kaki, pantat, alat kelamin. .. Inilah dua belas biji yang memiliki kegunaannya masing-masing berbeda. Inilah tata cara menyatukan segala kegunaannya. Oleh karena itu, inilah yang dikatakan oleh beliau.

2015)

\section{(Parmajaya,}

Dalam lontar Tri Kaya Parisudha/Resi Sesana 2.2b. juga disebutkan seperti berikut.

Telihên Sang Hyang Tri Kaya Parisudha, mengêt pwa kita ri pawkasan mami, hilang hyuntaring hala hayu, elikta ikang, malit ikang manah, sambega ujara manis.(Sujana, $\mathrm{tt}: 2$ )

Terjemahan.

Bercerminlah dari Sang Hyang Tri Kaya Parisudha. Ingatlah kamu tentang akibat dari perbuatan kamu. Hilangnya pikiranmu dari segala yang baik dan buruk, keinginanmu terhadap segala yang buruk, menyebabkan pikiranmu kerdil, dasari dengan mengucapkan kata yang manis.

(Parmajaya, 2015)

Berdasarkan apa yang tertuang di dalam lontar tri kaya parisudha, maka tri kaya parisudha tidak hanya sekadar mengendalikan pikiran, perkataan, dan perbuatan (manacika, wacika,dan kayika parisudha), tetapi yang perlu dikendalikan adalah semua indra yang melekat pada setiap manusia. Oleh sebab itu, di dalam lontar tri kaya parisudha diajarkan bagaimana tatacara orang mengendalikan indra untuk bisa menjadikan orang lain senang sebagai akibat dari perilaku yang dilakukan di dalam kehidupan sehari-hari di masyarakat.

Dalamkitab

suci

Sarasamuçcaya Sloka 73 disebutkan tri kaya (pikiran, perkataan, dan perbuatan), seperti di bawah ini. 


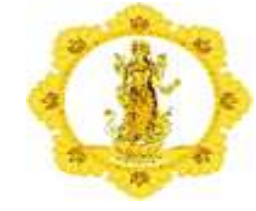

Manasā trịvịdham caịva
cāivā catur wịnham
Kayena trịvidham capi
dacakarma pathaccaret

Hana karmaphata ngaranya, karthaning indriya, sepuluh kwehnya, ulahakena, kramanya prawrttyaning manah sakareng, telu kwehnya; ulahaning wak, pat prawrttyaning kaya telu panda sapuluh prwrttyaning kaya, wak manah kengête.

(Kitab suci Sārasamuçcaya 73:61)

Terjemahan:

perbuatan yang timbul dari gerakan badan, perkataan, dan pikiran. Itulah patut diperhatikan(Kadjeng, 2005:61)

Konsep ajaran tri kaya parisudha yang sarat dengan nilai di atas nantinya dapat dijadikan dasar untuk menanamkan pendidikan karakter kepada para siswa, terutama terhadap nilai-nilai etika dan moral yang terkandung di dalam konsep ajaran tri kaya parisudha. Hal ini sejalan dengan pendapat Tirtarahardja, (2005:7) bahwa moral adalah yang sinkron dengan kata hati yang tajam yaitu yang benar-benar baik bagi manusia, sebagai manusia merupakan moral yang baik atau moral yang tinggi (luhur). Sebaliknya perbuatan yang tidak sinkron dengan kata hati yang tajam ataupun merupakan realisasi dari kata hati yang tumpul disebut moral yang buruk atau moral yang rendah (asor) atau lazim dikatakan tidak bermoral. Seseorang dikatakan
ADI WIDYA: Jurnal Pendidikan Dasar Volume. 2, Nomor 2 Oktober 2017

ISSN: 2527-5445

http://ejournal.ihdn.ac.id/index.php/A

$\mathrm{W}$

bermoral tinggi karena ia menyatukan diri dengan nilai-nilai yang tinggi, serta segenap perbuatannya merupakan peragaan dari nilai-nilai yang tinggi tersebut. Moral bertalian erat dengan keputusan kata hati, yang dalam hal ini bertalian erat dengan nilai-nilai, maka sesungguhnya moral itu adalah nilai-nilai kemanusiaan

Berdasarkan uraian di atas, untuk menanamkan pendidikan karakter yang baik harus dilalui dengan meningkatkan nilai moral dan keperibadian para siswa. Hal ini sejalan dengan pendapat Dantes, (2014:74) bahwa karakter berkaitan dengan pengetahuan moral, perasaan moral dan perilaku moral. Karakter yang baik terdiri atas pengđKahwarmhata namanya, y yang baik, keinginan untuk berbuat baik, dan berbuat kebaikan, atau kebiasaan pikiran, kebiasaan perasaan dalam hati dan kebiasaan berperilaku yang baik.

Menurut

Megawangi (2010:5), pendidikan karakter siswa adalah untuk mengukir akhlak melalui proses knowing the good, loving the good, dan acting the good. Yakni, suatu proses pendidikan yang melibatkan aspek kognitif, afektif, dan psikomotorik, sehingga akhlak mulia bisa terukir menjadi habit of the mind, heart, and hands. Dengan demikian, kurang tepat jika menganggap pendidikan karakter hanya urusan mata pelajaran agama atau PKN. Pendidikan karakter melekat pada mata pelajaran apapun. Bahkan, rasanya tidak adil jika pendidikan karakter hanya dibebankan dan menjadi tanggung jawab institusi sekolah.

Berdasarkan pernyataan di atas maka diketahui bahwa masalah kependidikan dewasa ini harus kembali kepada fungsi asalnya, yaitu 
ADI WIDYA: Jurnal Pendidikan Dasar Volume. 2, Nomor 2 Oktober 2017

ISSN: 2527-5445

http://ejournal.ihdn.ac.id/index.php/A

$\mathrm{W}$

menanamkan karakter positif warga negara sesuai dengan fungsi pendidikan yang tersurat dalam UU No. 20 Tahun 2003 tentang Sistem Pendidikan Nasional pada Pasal 3. Dalam UU tersebut dinyatakan bahwa pendidikan nasional berfungsi mengembangkan kemampuan dan membentuk karakter serta peradaban bangsa yang bermartabat dalam rangka mencerdaskan kehidupan bangsa. Dalam kaitannya dengan penelitian ini, maka karakter para siswa harus ditopang oleh nilai-nilai moral, etika, dan nilai-nilai budaya lokal, agar terwujud kehidupan yang damai (shanti) di dunia ini.

Menurut Diknas, (2010:5) mulai tahun ajaran 2011, seluruh tingkat pendidikan di Indonesia harus menyisipkandelapan belas nilai-nilai dalam pengembangan pendidikan budaya dan karakter bangsa. Kedelapan belas nilai-nilai dalam pendidikan karakter menurut Diknas adalah(1) religius adalahsikap dan perilaku yang patuh dalam melaksanakan ajaran agama yang dianutnya, toleran terhadap pelaksanaan ibadah agama lain, dan hidup rukun dengan pemeluk agama lain. (2) jujur adalah perilaku yang didasarkan pada upaya menjadikan dirinya sebagai orang yang selalu dapat dipercaya dalam perkataan, tindakan, dan pekerjaan, (3) toleransi adalah sikap dan tindakan yang menghargai perbedaan agama, suku, etnis, pendapat, sikap, dan tindakan orang lain yang berbeda dari dirinya, (4) disiplinadalah tindakan yang menunjukkan perilaku tertib dan patuh pada berbagai ketentuan dan peraturan, (5) kerja keras tindakan yang menunjukkan perilaku tertib dan patuh pada berbagai ketentuan dan peraturan, (6) kreatif adalah berpikir dan melakukan sesuatu untuk menghasilkan cara atau hasil baru dari sesuatu yang telah dimiliki, (7) mandiri adalah sikap dan perilaku yang tidak mudah tergantung pada orang lain dalam menyelesaikan tugastugas, (8) Demokratis adalah cara berfikir, bersikap, dan bertindak yang menilai sama hak dan kewajiban dirinya dan orang lain, (9) rasa ingin tahu adalah sikap dan tindakan yang selalu berupaya untuk mengetahui lebih mendalam dan meluas dari sesuatu yang dipelajarinya, dilihat, dan didengar, (10) semangat Kebangsaan adalah cara berpikir, bertindak, dan berwawasan yang menempatkan kepentingan bangsa dan negara di atas kepentingan diri dan kelompoknya, (11) cinta tanah air adalahadalah cara berpikir, bertindak, dan berwawasan yang menempatkan kepentingan bangsa dan negara di atas kepentingan diri dan kelompoknya, (12) menghargai prestasi adalah sikap dan tindakan yang mendorong dirinya untuk menghasilkan sesuatu yang berguna bagi masyarakat, dan mengakui, serta menghormati keberhasilan orang lain, (13) 
bersahabat/komunikatif

adalah sikap dan tindakan yang mendorong dirinya untuk menghasilkan sesuatu yang berguna bagi masyarakat, dan mengakui, serta menghormati keberhasilan orang lain, (14) cinta damaiadalah sadalah sikap dan tindakan yang mendorong dirinya untuk menghasilkan sesuatu yang berguna bagi masyarakat, dan mengakui, serta menghormati keberhasilan orang lain, (15) gemar membaca adalah kebiasaan menyediakan waktu untuk membaca berbagai bacaan yang memberikan kebajikan bagi dirinya, (16) peduli lingkungan adalah sikap dan tindakan yang selalu berupaya mencegah kerusakan pada lingkungan alam di sekitarnya, dan mengembangkan upayaupaya untuk memperbaiki kerusakan alam yang sudah terjadi, (17) peduli sosial adalah sikap dan tindakan yang selalu ingin memberi bantuan pada orang lain dan masyarakat yang membutuhkan dan (18) tanggung jawab adalah sikap dan perilaku seseorang untuk melaksanakan tugas dan kewajibannya, yang seharusnya dia lakukan, terhadap diri sendiri, masyarakat, lingkungan (alam, sosial dan budaya), negara dan Tuhan Yang Maha Esa.

\section{Fungsi Pendididkan Karakter}

\section{$\mathrm{W}$}

Fungi pedndidikan karakter adalah untuk mengembangkan kemampuan dan membentuk bakat serta peradaban bangsa yang bermartabat dalam mencerdasakan kehidupan berbangsa. Secara lebih khusus dan terperinci Kemendiknas (2011: 9--10) menyebutkan bahwa pendidikan karakter mempunyai fungsi sebagai berikut pembentukan dan pengembangan potensi. Pendidikan karakter berfungsi membentuk dan mengembangkan potensi manusia atau warga negara Indonesia agar berpikir baik, berhati baik dan berperilaku sesuai dengan falsafah hidup Pancasila, (2) perbaikan dan penguatan. Pendidikan karakter berfungsi untuk memperbaiki karakter manusia dan warga negara Indonesia yang bersifat negatif dan membentuk peran keluarga, satuan pendidikan masyarakat dan pemerintah untuk ikut berpartisipasi dan bertanggung jawab dalam pengembangan potensi manusia atau warga negara menuju bangsa yang berkarakter, maju, mandiri dan sejahtera, dan (3) penyaringan. Pendidikan karakter bangsa berfungsi memilah nilai-nilai budaya bangsa sendiri dan menyaring budaya bangsa lain yang positif untuk menjadi karakter manusia dan warga negara Indonesia agar lebih bermanfaat.

\section{Komponen Pendidikan Karakter}

Pendidikan karakter merupakan proses pembentukan budi pekerti plus yang melibatkan aspek pengetahuan (cognitive), perasaan (feeling), dan tindakan (action). Jika dikaitkan dengan konsep etika Hindu, maka pikiran (manacika) relevan dengan pengetahuan 
(cognitif), perkataan (wanacika) relefan dengan (afektif), dan perilaku (psikomotor) relefan dengan (kayika). Jika ketiga aspek/ranah tersebut bisa dintegrasikan, ketiganya akan menciptakan satu tatanan terpadu yang bermuara pada proses pembentukan karakter. Peserta didik sebagai subjek didik di sekolah perlu diberikan satu pengalaman dan pembelajaran yang mencakup aspek pengetahuan, perasaan, dan tindakan. Dengan modal pengetahuan, peserta didik dapat memiliki ilmu pengetahuan agar siap digunakan sebagai bekal pada proses kehidupan yang akan dialami di masa yang akan datang. Melalui perasaan, ilmu pengetahuan yang tidak terbatas akan dikendalikan dan dikembangkan dengan mempertimbangkan aspek emosional. Adapun tindakan yang dihasilkan merupakan perwujudan dari proses pengembangan pengetahuan (cognitive) melalui pertimbangan perasaan (feeling). Secara tersirat dapat diambil satu konsep pemikiran bahwa proses pendidikan yang bermuara pada pembelajaran (baik secara kurikuler, eksrtakurikuler, maupun kokurikuler) tidak dapat dipisahkan satu dengan lainnya yang melibatkan ketiga aspek kognitif, afektif, maupun psikomotor. Ketiganya merupakan satu integrasi yang tidak dapat dipisahkan satu dengan lainnya.

Jika hal di atas dikaitkan dengan pendapat Lickona maka pendidikan karakter yang benar harus melibatkan aspek knowing the good (moral knowing), desiring the good atau loving the good (moral feeling), dan acting the good (moral action).

a. Moral knowing (pengetahuan moral).
Moral knowing (pengetahuan moral) berhubungan dengan bagaimana seorang individu mengetahui sesuatu nilai yang abstrak yang dijabarkan dalam 6 sub komponen, antara lain: (a) moral awareness (kesadaran moral), (b) knowing moral values (pengetahuan nilai moral), (c) perspective-taking

(memahami sudut pandang lain), (d) moral reasoning (penalaran moral), (e) decision-making (membuat keputusan), (f) selfknowledge (pengetahuan diri)

b. Moral feeling (sikap moral).

Moral feeling (sikap moral) merupakan tahapan tingkat lanjut pada komponen karakter yang dijabarkan dalam 6 sub komponen, antara lain: (a) Conscience (nuranI), (b) Self-esteem (harga diri), (c) Empathy (empati), (d) Loving the good (cinta kebaikan), (e) Selfcontrol (kontrol diri) dan $(f)$ Humility (rendah hati).

c. Moral action (perilaku moral).

Moral action (perilaku moral) dibangun atas 3 sub komponen antara lain: (a) Competence (kompetensi), (b) Will (keinginan) dan (c) Habit (kebiasaan).

\section{Susila Sebagai Dasar Pendidikan Karakter}

Jika dicermati secara saksama, sebenarnya buah pikiran, perkataan dan perbuatan yang dilakukan oleh manusia merupakan bentuk karma. Setiap karma pasti ada akibatnya. Perbuatan yang baik (subhakarma) akan menghasilkan 
pahala yang baik, atau dengan kata lain karma baik pahalanya pasti akan baik. Perbuatan yang buruk (asubhakarma) akan menghasilkan buah yang tidak baikatau dengan kata lain karma jelek yang dilakukan oleh seseorang pasti pahalanya juga buruk.Pahala tidak menjadi tujuan karma manusia. Oleh sebab itu dalam kehidupan di dunia ini bekerjalah selalu dengan tidak mengharapkan hasil. Jika manusia mampu melakukan kerja dengan tulus ikhlas, maka bisa dikatakan manusia itu telah mengamalkan ajaran agama (Hindu). Jika dicermati secara seksama, maka sebenarnya agama merupakan dasar dari tata susila, sebagai pedoman bagi setiap umat manusia untuk berperilaku baik dan benar.

Dalam kitab suci Sarasamuccaya160 disebutkan sebagai berikut.

Silam pradhanam puruse tadyaseha pranasyati,

$\mathrm{Na}$ tasya jivitenartho duhsilam kinprayojanam.

Sila ktikang pradhana ring dadi wwang, hana prawrtti ning

dadiwwang dussila, aparan ta prayojananika ring hurip, ring wibha, ring kaprajinan, apan wyartha ika kabeh, yan tan hana silayukti.

(Kitab

suci

Çarasamисcay a 160)

Terjemahan.

Susila itu adalah yang paling utama, pada titisan sebagai manusia. Jika ada prilaku titisan sebagai manusia itu tidak susila, apakah maksud orang itu dengan hidupnya, dengan kekuasaan, dengan kebijaksanaan, sebab sia-sia itu semuanya jika tidak ada kesusilaan.

(Kadjeng, 2005:128)

Tata susila pada dasarnya bertujuan untuk membina hubungan yang selaras/rukun antara seseorang dan orang lainnya, masyarakat dengan masyarakat lainnya, dan manusia dengan alam sekitarnya. Tata susila membina watak manusia untuk menjadi anggota keluarga yang baik, anggota masyarakat yang baik, putra bangsa yang berbudi pekerti luhur dan berkepribadian mulia sehingga tercapai kebahagiaan abadi (anandha). Oleh sebab itu di dalam pendidikan formal mulai dari tingkat PAUD (pendidikan anak usia dini) sampai di perguruan tinggi, di lingkungan keluarga, di lingkungan masyarakat, ajaran tata susila ini harus selalu diperaktikkan.

Berdasarkan hal di atas, Lickona, (1991:43) menyatakan bahwa pendidikan karakter adalah suatu usaha yang disengaja untuk membantu seseorang sehingga ia dapat memahami, memperhatikan, dan melakukan nilai-nilai etika yang inti. Pendidikan Karakter Menurut Kertajaya (2010:17) adalah ciri khas yang dimiliki oleh suatu benda atau individu. Ciri khas tersebut adalah asli dan mengakar pada kepribadian benda atau individu tersebut, serta merupakan "mesin" yang mendorong bagaimana seorang bertindak, bersikap, berucap, dan merespon sesuatu

\begin{tabular}{|c|c|}
\hline & \\
\hline $\begin{array}{l}\text { 5. Implementasi } \\
\text { Karakter dalam } \\
\text { Sikap Susila }\end{array}$ & $\begin{array}{l}\text { Pendidikan } \\
\text { Membentuk }\end{array}$ \\
\hline
\end{tabular}


ADI WIDYA: Jurnal Pendidikan Dasar Volume. 2, Nomor 2 Oktober 2017

ISSN: 2527-5445

http://ejournal.ihdn.ac.id/index.php/A

Untuk menanamkan pendidikan karakter kepada para siswa sekolah dasar (SD) berdasarkanajaran susila/etika (tri kaya parisudha) dapat dilakukan beberapa cara sebagai berikut.

1. Tanamkan dasar konsep keyakinan kepada para siswa berdasarkan acuan atau pedoman alat ukur yang mengacu pada model taksonomi nilai berbasis tri kaya parisudha yang telah dikembangkan.

2. Latih para siswa untuk selalu berpikir positif, kearah kebaikan sebagai dasar perilaku perkataan dan perbuatan yang baik dan suci

3. Latih siswa menaati aturanaturan dalam kehidupan beragama, berbangsa, dan bernegara

4. Didik siswa untuk menaati pandangan atau sistem nilai secara menyeluruh dan mendalam, terutama tentang akhlak dan moral yang dianggap benar dan adil

5. Didik para siswa untuk mampu bertingkah laku (berpikir, berkata-kata, berbuat) yang benar, baik di lingkungan keluarga, sekolah,maupun masyarakat

6. Didik para siswa agar selalu mengembangkan ide untuk mempertahankan dan mengembangkan produk kebudayaan.

7. Mendidik para siswa untuk memahami tentang tatacara beragama yang inclusif, sehingga para siswa tidak malu untuk beragama Hindu

8. Latih para siswa untuk mengetahui, dan memahami

\section{W}

serta mengamalkan tata cara melakukan persembahyangan

9. Didik para siswa untuk memahami nyanyian ketuhanan (dharmagita) sebagai salah satu cara persembahan kehadapan Ida Hyang Widhi Wasa/Tuhan Yang maha Esa

10. Didik para siswa untuk memahami dan mengetahui fungsi tarian sakral sebagai pelengkap dan pengiring upacara keagamaan

11. Didik para siswa untuk menjadikan adat dan kebiasaan yang dilakukan dalam kehidupan keberagamaan menjadi suci

12. Mendidik para siswa untuk memahami berbagai kegiatan upacara dalam panca yadnya (dewa yadnya, manusa yadnya, pitra yadnya, rsi yadnya dan bhuta yadnya)

13. Melatih siswa untuk bersadhana (melakukan pemusatan pikiran secara sistematis dan metodis) agar dalam melaksanakan persembahyangan pikiran siswa menjadi fokus terhadap apa yang dituju.

14. Mendidik para siswa untuk memiliki kesadaran beragama

15. Mendidik para siswa untuk selalu merasa dekat dengan Ida Hyang Widhi Wasa/Tuhan Yang Maha Esa, antar sesame manusia dan lingkungan sekitarnya.

16. Membimbing para siswa untuk memiliki kedewasaan intelektual, dengan menyadari bahwa agama dapat dijadikan pegangan hidup pada saat para siswa menginjak dewasa 
17. Mendidik para siswa untuk selalu meyakini ajaran agamanya sendiri

18. Mendidik para siswa untuk belajar agama dengan menggunakan pandangan kritis (logika). Artinya dengan tidak melihat bahwa agama bukan hal yang berkaitan dengan masalah niskala, tetapi mempelajari dan memandang agama sebagai ajaran yang masuk akal/logis

19. Mendidik para siswa untuk selalu berbuat baik dan benar dalam kehidupan di sekolah, di lingkungan keluarga, dan di masyarakat.

\section{SIMPULAN}

Berbagai kasus yang terjadi di Indonesia seperti korupsi, premanisme, perkelahian antar siswa, pemerkosaan, pelecehan seksual, begal motor, perampokan dan bahkan pembunuhan disebabkan oleh runtuhnya karakter manusia.Upaya yang bisa dilakukan untuk menanggulangi fenomena tersebut adalah dengan jalan memperbaiki karakter masing-masing individu melalui pendidikan karakter yang harus dibentuk mulai usia dini. Di sekolah dasar (SD) pendidikan karakter dapat ditransformasikan melalui pembelajaran di kelas dan melalui kegiatan ekstrakurikuler. Selain itu pihak sekolah terutama komponen yang ada di masingmasing satuan pendidikan dalam hal ini guru dan staf sekolah harus dapatmenjadi model yang baik di dalam penanaman pendidikan karakter. Pihak sekolah harus menjalin kerja sama dengan orang tua siswa, aparat keamanan, instansi terkait dan para tokoh dan pemuka agama dalam mentransformasikan pendidikan karakter. Melalui kerjasama antara komponen tri sentra pendidikan (keluarga, sekolah dan masyarakat) diharapkan penanaman pendidikan karakter dapat terlaksana dengan optimal. Melalui kegiatan eksrtakurikuler diharapkan sikap dan perilaku positif para peserta didik dapat terbentuk sesuai dengan nilainilai keperibadian bangsa Indonesia yang berkarakter.

\section{DAFTAR PUSTAKA}

Budi Hardiman. 2001. Pendidikan Moral sebagai Pendidikan Keadilan dalam Pendidikan: Kegelisahan Sepanjang Zaman. Yogyakarta: Kanisius

Dantes, Nyoman. 2014. Landasan Pendidikan Tinjauan dari Dimensi Makropaedagogis, Singaraja:Undiksha

Fatchul Mu'in. 2011. Pendidikan Karakter: Konstruksi Teoretik \& Praktik. Jogjakarta: Ar-Ruzz Media.

Kadjeng, I Nyoman, dkk. 2005.Sarasamuçcaya, Jakarta:Pustaka Mitra Jaya.

Kertajaya H .2010 .Pendidikan Karakter.Jakarta: Gramedia

Lickona, Thomas. 199.1 Educating for Character. How Our School can Teach Respect and Responsibility. New York: Bantam Books.

Lickona, Thomas. 2004 Character Matters. How To Help Our Children Develop Good Judgment, Integrity, and Other Essencial Virtues. New York: Bantam Books. 
ADI WIDYA: Jurnal Pendidikan Dasar Volume. 2, Nomor 2 Oktober 2017

ISSN: 2527-5445

http://ejournal.ihdn.ac.id/index.php/A

Megawangi, Ratna, 2010. Pengembangan Program Pendidikan Karakter di Sekolah, Pengalaman Sekolah Karakter. Makalah. IHF,JKT .

Sekretariat Direktoral Jendral Pendidikan Dasar Kementerian Pendidikan Nasional. 2011. Mencari Karakter Terbaik dari Belajar Sejarah. Jakarta: Kementerian Pendidikan Nasional.

Nilai Pembentuk Karakter Dalam Mata Pelajaran). Yogyakarta: Familia.

Undang-Undang RI No. 20 Tahun 2003. Sistem Pendidikan Nasional. Bandung: Fokusmedia.

Zainal Aqib. 2011. Pendidikan Karakter Membangun Perilaku Positif Anak Bangsa. Bandung: CV. YRAMA WIDYA.

Zubaedi. 2005. Pendidikan Berbasis Masyarakat (Upaya

Sekretariat Direktoral Jendral Pendidikan Dasar Kementerian Pendidikan Nasional. 2011. Pendidikan Karakter dalam Pembelajaran PKn. Jakarta: Kementerian Pendidikan Nasional.

Menawarkan Solusi Terhadap Berbagai Problem Sosial). Yogyakarta: PUSTAKA PELAJAR.

Lontar Tri Kaya Parisudha/Resi Sesana, Denpasar:Unit Pelaksanaan Dokumentasi Kebudayaan Bali.

Sri Narwanti. 2011. Pendidikan Karakter (Pengintegrasian 18 